\title{
Regime próprio de Previdência Social. Taxa de administração: custeio das despesas administrativas ${ }^{1}$
}

\author{
Vanessa Amaro Candido ${ }^{2}$
}

\section{Resumo}

Este trabalho trata da taxa de administração como forma de custeio das despesas administrativas do Regime Próprio de Previdência Social.

Palavras-Chave: Regime Próprio de Previdência. Taxa de Administração.

\section{Introdução}

Regime Próprio de Previdência Social, segundo o conceito apresentado pela Orientação Normativa/SPS no 03, de 12 de agosto de 2004, publicada no D. O. U. de 17/08/2004, em seu art. 2ㅇ, I, é “o sistema de previdência, estabelecido no âmbito de cada ente federativo, que assegure, por lei, a servidor titular de cargo efetivo, pelo menos os benefícios de aposentadoria e pensão por morte previstos no art. 40 da Constituição Federal".

No Brasil, as regras gerais para a organização e o funcionamento dos Regimes Próprios de Previdência Social dos servidores públicos estão dispostas na Lei no 9.717, de 27 de novembro de 1998, cuja definição e aplicação dos parâmetros e diretrizes gerais seguem as disposições da Portaria no 4.992/99, de 05 de fevereiro de 1999, publicada no D. O. U. de 08/02/1999.

Segundo essa legislação a organização do Regime Próprio pode se dar na forma de departamento interno do ente estatal ou sob a forma de uma entidade gestora autônoma, com variadas modelagens de estrutura organizacional e administrativa.

1 Artigo apresentado como Trabalho de Conclusão de Curso ao Curso de Especialização em Direito do Estado - Direito Administrativo da Universidade Estadual de Londrina. Professor Orientador: Erivaldo Ribeiro dos Santos. Juiz Federal em Maringá, Mestre e Professor do Curso de Direito da Universidade Estadual de Maringá - UEM.

2 Aluna da Pós-Graduação em Direito do Estado - área de Concentração em Direito Administrativo - pela Universidade Estadual de Londrina; Bacharel em Direito pela Universidade Estadual de Maringá - UEM; Funcionária pública municipal efetiva; Pós-graduada em Administração Pública pela Faculdade Estadual de Ciências e Letras de Campo Mourão - FECILCAM 
A Lei no 9.717/08 faculta a possibilidade de criação de um fundo com finalidade previdenciária, integrado por recursos provenientes de contribuições e de compensação previdenciária e por bens, direitos e ativos, para viabilização do financiamento do Regime Próprio, que deve se dar com base nas contribuições dos segurados e do Município, destinadas exclusivamente ao pagamento dos benefícios previdenciários, limitando o custeio das despesas administrativas a $2 \%$ sobre o total da remuneração, proventos e pensões dos segurados, com relação ao exercício financeiro anterior.

\section{Regime próprio de previdência social}

O direito dos servidores públicos titulares de cargos efetivos ao regime de previdência passou a integrar o texto do art. 40 da Constituição Federal de 1988 a partir da redação dada pela Emenda Constitucional no 20, de 15/12/1998:

Art. 40 - Aos servidores titulares de cargos efetivos da União, dos Estados, do Distrito Federal e dos Municípios, incluídas suas autarquias e fundações, é assegurado regime de previdência de caráter contributivo, observados critérios que preservem o equilíbrio financeiro e atuarial e o disposto neste artigo.

Depois dessa alteração o sistema previdenciário brasileiro vem sofrendo inúmeras transformações, destacando a previdência dos servidores públicos, colocado estrategicamente no centro da reforma previdenciária ${ }^{3}$.

Esse conteúdo foi novamente alterado pela Emenda Constitucional no 41, de 19/12/2003, que Ihe acrescentou ao caráter contributivo o solidário, bem como impôs aos servidores inativos e aos pensionistas a obrigação contributiva:

Art. 40. Aos servidores titulares de cargos efetivos da União, dos Estados, do Distrito Federal e dos Municípios, incluídas suas autarquias e fundações, é assegurado regime de previdência de caráter contributivo e solidário, mediante contribuição do respectivo ente público, dos servidores ativos e inativos e dos pensionistas, observados critérios que preservem o equilíbrio financeiro e atuarial e o disposto neste artigo.

3 BRASIL. Ministério da Previdência e Assistência Social. Gushiken, L. Regime Próprio de Previdência dos Servidores: como implementar? Uma visão prática e teórica. Brasília: MPAS, 2002. P. 29. 
A legislação infraconstitucional também cuidou do conceito de Regime Próprio de Previdência Social - RPPS, tendo sido expressamente inserido no corpo da Orientação Normativa SPS no 21, de 21/06/2000:

I - DEFINIÇÃO DE REGIME PRÓPRIO DE PREVIDÊNCIA SOCIAL

1. Entende-se por regime próprio de previdência social, a partir de 27 de agosto de 1960, data da publicação da Lei no 3.807 , de 1960, o que assegura a servidor público, ainda que mediante convênio, pelo menos aposentadoria por invalidez, por idade e voluntária, com proventos integrais ou proporcionais, conforme o caso, e pensão por morte.

A inserção do conceito de RPPS no corpo de um dispositivo legal pacificou as discussões que gravitavam quanto àqueles Regimes que não englobavam em suas leis a concessão de todos os benefícios previstos pelo Regime Geral de Previdência Social - RGPS, tornando-se mansa a existência de RPPS que assegura exclusivamente os benefícios de aposentadoria por invalidez, por idade e voluntária e de pensão por morte.

Incompreensível, entretanto, que a ON/SPS no 21/2000 tenha excluído do conceito de RPPS a aposentadoria compulsória, prevista na redação original do art. 40 da Constituição Federal, esse fato foi corrigido pela Orientação Normativa no 001, de 29/05/2001, que a revogou, trazendo nova definição:

I- DEFINIÇÃO DE REGIME PRÓPRIO DE PREVIDÊNCIA SOCIAL

1. Entende-se por regime próprio de previdência social o que assegura a servidor público titular de cargo efetivo, ainda que mediante convênio, pelos menos aposentadoria e pensão por morte.

Eventuais dúvidas que se mantivessem quanto à abrangência da aposentadoria compulsória no conceito de RPPS foram sanadas quando da inserção da Portaria MPAS no 4.992/99, pela Portaria no 777, de 10/07/2002, que expressamente previu a concessão das aposentadorias e da pensão por morte previstas no art. 40 da Constituição Federal:

Art. 10 [...]

Parágrafo único. Entende-se por regime próprio de previdência social o que assegura por lei, inclusive constituição estadual ou lei orgânica distrital ou municipal, a servidor público titular de cargo efetivo, pelo menos as aposentadorias e a pensão por morte previstas no art. 40 da Constituição Federal. 
Revogado pela Portaria no 838 , de 28/07/2004, o conteúdo do parágrafo único do art. 1ㅇ da Portaria no 4.992/99 foi recepcionado pela Orientação Normativa/SPS no 03, de 12/08/2004, em seu art. 2으, I:

CAPÍTULO I- DAS DEFINIÇÕES

Art. 2o Para os efeitos desta Orientação Normativa, considera-se:

I - regime próprio de previdência social, o sistema de previdência, estabelecido no âmbito de cada ente federativo, que assegure, por lei, a servidor titular de cargo efetivo, pelo menos os benefícios de aposentadoria e pensão por morte previstos no art. 40 da Constituição Federal.

A Orientação Normativa SPS no 02, de 05/09/2002, que revogou a ON/SPS no 001/2001, também abordou esse conteúdo:
CAPÍTULO I - DA DEFINIÇÃO DE REGIME PRÓPRIO DE PREVIDÊNCIA SOCIAL
Art. 1을 Entende-se por regime próprio de previdência social o que assegure por lei, inclusive constituição estadual ou lei orgânica distrital ou municipal, a servidor público pelo menos as aposentadorias e pensão por morte previstas no art. 40 da Constituição Federal.

Esses dispositivos também trouxeram um consenso quanto ao aspecto formal de instituição do Regime Próprio de Previdência, passando a ser aceita, indubitavelmente, a sua criação por constituição estadual ou lei orgânica distrital ou municipal, não necessitando de lei específica.

A principal legislação aplicável ao RPPS constitui-se nos seguintes instrumentos:

- Emenda Constitucional no 20, de 15/12/1998, que modifica o sistema de previdência social, estabelece normas de transição e dá outras providências;

- Emenda Constitucional no 41, de 19/12/2003, que modifica os arts. 37, 40, 42, 48, 96, 149 e 201 da Constituição Federal, revoga o inciso IX do § 3ㅇ do art. 142 da Constituição Federal e dispositivos da Emenda Constitucional no 20, de 15 de dezembro de 1998 e dá outras providências;

- Emenda Constitucional no 47, de 06/07/2005, que altera os arts. 37, 40, 195 e 201 da Constituição Federal, para dispor sobre a previdência social, e dá outras providências;

- Lei no 9.717, de 27/11/1998, que dispõe sobre a organização e o funcionamento dos regimes próprios de previdência social dos servidores públicos da União, dos Estados, do 
Distrito Federal e dos Municípios, dos Militares dos Estados e do Distrito Federal e dá outras providências;

- Portaria no 4.992, de 05/02/1999, que dispõe sobre a regulamentação da Lei no 9.717/98;

- Lei no 9.796, de 05/05/1999, que dispõe sobre a compensação financeira entre o RGPS e os regimes de previdência dos servidores da União, dos Estados, do Distrito Federal e dos Municípios, nos casos de contagem recíproca de tempo de contribuição para efeito de aposentadoria, e dá outras providências;

- Decreto no 3.112, de 06/07/1999, que dispõe sobre a regulamentação da Lei no 9.796, que versa sobre compensação financeira entre os regimes;

- Portaria MPAS no 6.209, de 16/12/1999, que dispõe sobre a regulamentação da Lei no

9.796, que versa sobre compensação financeira entre os regimes;

- Resolução CMN no 3.244, de 28/10/2004, que dispõe sobre as aplicações dos recursos dos regimes próprios de previdência social instituídos pela União, pelos Estados, pelo Distrito Federal ou por Municípios;

- Decreto no 3.788, de 11/04/2001, que institui, no âmbito da Administração Pública Federal, o Certificado de Regularidade Previdenciária - CRP;

- Portaria no 172, de 11/02/2005, que dispõe sobre a emissão do Certificado de Regularidade Previdenciária - CRP;

- Lei Complementar no 101, de 04/05/2000, que estabelece normas de finanças públicas voltadas para a responsabilidade na gestão fiscal e dá outras providências (Lei de Responsabilidade Fiscal).

\section{Personalidade jurídica da entidade gestora}

Um Regime Próprio de Previdência Social - RPPS de um ente público necessita de uma entidade que se incumba de sua gestão ${ }^{4}$. Essa organização pode se dar na forma de departamento interno do ente estatal (órgão integrante da estrutura da administração pública) ou sob a forma de uma entidade gestora autônoma, a qual pode se apresentar com variadas modelagens de estruturas organizacionais e administrativas.

\footnotetext{
4 BRASIL. Ministério da Previdência e Assistência Social. Rabelo, F. Regimes Próprios de Previdência: Modelo Organizacional, Legal e de Gestão de Investimentos. Brasília: MPAS / SPS, 2001. P. 13.
} 
A Portaria MPAS no 4.992/99 veda expressamente no parágrafo único do art. 10 a existência de mais de um regime próprio de previdência social dos servidores públicos, e de mais de uma unidade gestora do respectivo regime próprio de previdência social em cada ente estatal, trazendo na seqüência o conceito de unidade gestora: "Parágrafo único. Entende-se como unidade gestora de regime próprio de previdência social, aquela com a finalidade de gerenciamento e operacionalização do respectivo regime".

A Orientação Normativa SPS no 03/2004, apresenta o conceito de unidade gestora:

Art. 2ㅇ Para os efeitos desta Orientação Normativa, considera-se: [...]

III - unidade gestora, a entidade ou órgão integrante da estrutura da administração pública de cada ente federativo que tenha por finalidade a administração, o gerenciamento e operacionalização do regime próprio, incluindo a arrecadação e gestão de recursos e fundos previdenciários, a concessão, o pagamento e a manutenção dos benefícios.

A entidade gestora pode assumir várias personalidades jurídicas, como autarquia, fundação de direito público e serviço social autônomo.

No Estado do Paraná, o Sistema de Seguridade Funcional é gerido pela PARANAPREVIDÊNCIA, que possui natureza jurídica de serviço social autônomo.

\section{Fundo previdenciário}

A Lei no 9.717/98 prevê em seu art. 6 a possibilidade de criação do fundo integrado de bens, direitos e ativos, com finalidade previdenciária:

Art. 6ㅇ Fica facultada à União, aos Estados, ao Distrito Federal e aos Municípios, a constituição de fundos integrados de bens, direitos e ativos, com finalidade previdenciária, desde que observados os critérios de que trata o artigo 1으 e, adicionalmente, os seguintes preceitos:

I - (Revogado pela MP no 2.187-13, de 24/08/2001)

II - existência de conta do fundo distinta da conta do Tesouro da unidade federativa;

III - (Revogado pela MP no 2.187-13, de 24/08/2001);

IV - aplicação de recursos, conforme estabelecido pelo Conselho Monetário Nacional;

V - vedação da utilização de recursos do fundo de bens, direitos e ativos para empréstimos de qualquer natureza, inclusive à União, aos Estados, ao Distrito Federal e aos Municípios, a entidades da administração indireta e aos respectivos segurados;

VI - vedação à aplicação de recursos em títulos públicos, com exceção de títulos do Governo Federal; 
VII - avaliação de bens, direitos e ativos de qualquer natureza integrados ao fundo, em conformidade com a Lei 4.320, de 17 de março de 1964 e alterações subseqüentes;

VIII - estabelecimento de limites para a taxa de administração, conforme parâmetros gerais;

IX - constituição e extinção do fundo mediante lei.

Esse conteúdo é trazido também pelo art. 17 da Portaria n -4.992/99.

\section{Destinação dos recursos}

A Portaria no 4.992/99 traz em sue art. 8 a vedação da utilização de recursos do Regime Próprio para fins de assistência médica e financeira de qualquer espécie, somente sendo possível a sua utilização para pagamento de benefícios previdenciários dos respectivos regimes, ressalvadas as despesas administrativas estabelecidas no art. 60, inciso VIII, da Lei no 9.717/98, observado os limites de gastos estabelecidos em parâmetros gerais:

Art. 6ㅇ Fica facultada à União, aos Estados, ao Distrito Federal e aos Municípios, a constituição de fundos integrados de bens, direitos e ativos, com finalidade previdenciária, desde que observados os critérios de que trata o artigo 10 e, adicionalmente, os seguintes preceitos: [...]

VIII - estabelecimento de limites para a taxa de administração, conforme parâmetros gerais;

\section{Taxa de administração}

A previsão de limites à taxa de administração é trazida pelo inciso VIII do art. 60 da Lei no 9.717/98, preceito de cumprimento obrigatório para os Regimes Próprios de Previdência Social que pretendam constituir fundos integrados de bens, direitos e ativos, com finalidade previdenciária.

Esse preceito é assimilado pela Portaria no 4.992/99 em seu art. 17, inciso VIII, cujos parâmetros gerais de aplicação são fixados em seu § 3ㅇ:

Art. 17. Fica facultada à União, aos Estados, ao Distrito Federal e aos Municípios, a constituição de fundos integrados de bens, direitos e ativos, com finalidade previdenciária, desde que observados os critérios de que trata o artigo 2 o desta Portaria e, adicionalmente, os seguintes preceitos: [...]

VIII - estabelecimento de limites para a taxa de administração, conforme estabelecido no § 3 o deste artigo; [...]

§ 3으 A taxa de administração prevista no inciso VIII deste artigo, a ser utilizada na cobertura das despesas administrativas do regime próprio de previdência social, será de até dois pontos percentuais do valor total da remuneração, proventos e pensões dos segurados vinculados ao regime próprio de previdência social, 
relativamente ao exercício financeiro anterior." (Alterado pela Portaria no 1.348 , de 19/07/2005 - Publicada no D. O. U. de 21/07/2005)

Em sua redação original o § 3으 do art. 17 da Portaria no 4.992/99 tinha como base para o cálculo da taxa de administração o valor total da remuneração dos servidores e dos militares, incluindo o valores dos proventos e pensões dos segurados vinculados ao regime próprio de previdência social somente a partir da redação dada pela Portaria $\mathrm{n}$ ㅇ 1.317 , de 19/09/2003, publicada no D. O. U. de 19/09/2003.

$\mathrm{Na}$ verificação do atendimento do limite definido no parágrafo anterior, não são computadas as despesas decorrentes exclusivamente do resultado das aplicações de recursos em ativos financeiros, na forma preceituada pelo $\S 4$ 을 do art. 17 da Portaria № 4.992/99, acrescentado pela Portaria no 1.317, de 17/09/2003:

§ 4ㅇ Na verificação do atendimento do limite definido no parágrafo anterior, não serão computadas as despesas decorrentes exclusivamente do resultado das aplicações de recursos em ativos financeiros de que trata o inciso IV deste artigo.

A Taxa de Administração figura assim como uma exceção na destinação dos recursos previdenciários, primordialmente destinados ao custeio dos benefícios.

Desde que observado o limite de dois pontos percentuais do valor total da remuneração, proventos e pensões dos segurados vinculados ao regime próprio de previdência social, relativamente ao exercício financeiro anterior, ao final do exercício financeiro, o Regime Próprio, por deliberação da instância coletiva de decisão, poderá constituir reservas com eventuais sobras do custeio administrativo, cujos recursos somente será utilizados para os fins a que se destina a taxa de administração, sendo que o montante não poderá ultrapassar a totalidade das efetivas despesas administrativas do exercício anterior, nos termos do $\S 80$ do art. 17 da Portaria $\mathrm{n}$ - 4.992/99, acrescido pela Portaria $\mathrm{n}$ 은 1.348, de 19/07/2005, publicada no D. O. U de 21/07/2005:

§ 8음 Desde que observado o limite previsto no § 3으, ao final do exercício financeiro, o regime próprio de previdência social, por deliberação da instância coletiva de decisão, poderá constituir reservas com eventuais sobras do custeio administrativo, cujos recursos somente serão utilizados para os fins a que se destina a taxa de administração, sendo que o montante não poderá ultrapassar a totalidade das efetivas despesas administrativas do exercício anterior. 
A possibilidade de constituição de reservas já refletia o entendimento do Tribunal de Contas do Paraná, que em face de reiteradas dúvidas dirigidas à Diretoria de Contas Municipais sobre alguns aspectos orçamentários, apresenta no documento "QUESTÕES PERTINENTES AO ORÇAMENTO DE 2005" considerações, no intuito de possibilitar tratamento uniformizado na elaboração dos orçamentos do exercício de 2005:

\begin{abstract}
TRIBUNAL DE CONTAS DO ESTADO DO PARANÁ
As despesas oriundas do gerenciamento do RPPS (sendo exemplos as contas 3190.11 - VENCIMENTOS E VANTAGENS FIXAS e 3390.39 - OUTROS SERVIÇOS DE TERCEIROS - PESSOA JURÍDICA) deverão ser custeadas exclusivamente com recursos da taxa de administração, fonte 01001-Recursos do Tesouro (Descentralizados) - Exercício Corrente; todos os demais valores são considerados reservas previdenciárias. A fonte servirá de referência para a verificação do atendimento do limite máximo para as despesas feitas com a taxa de administração. Nos termos fixados pela Portaria MPS no 1317/2003, a taxa de administração é de até $2 \%$ do valor total da remuneração, proventos e pensões dos segurados vinculados ao Regime Próprio de Previdência, relativamente ao exercício anterior.

É pertinente esclarecer que a taxa de administração para o gerenciamento do Fundo de Previdência, poderá ser por dentro (utilizar-se de recursos previdenciários, conforme possibilita o art. 10, III, da Lei no 9.717/98), ou por fora (repassados além dos recursos previdenciários), cabendo à lei local regulamentar a forma, segundo faculta o art. 60 da Leio no 9.717/98. Inclusive, definir quanto à devolução da eventual sobra anual, apenas no caso de serem repassados por fora, quando poderá integrar os recursos para os benefícios previdenciários ou ser devolvida ao Ente patronal. Quando se tratar de recursos do próprio Fundo não é procedente a devolução da sobra ao Ente patronal, mas a reintegração ao patrimônio Previdenciário. A manutenção da sobra do recurso para utilização em despesas administrativas não deve ser cogitada, visto que, conforme já exposto, os gastos anuais são limitados. (grifo nosso)
\end{abstract}

\title{
6 Despesas administrativas
}

O § 60 do art. 17 da Portaria no 4.992/99, acrescentado pela Portaria no 1.348, de $19 / 07 / 2005$, traz os elementos que se caracterizam como despesas administrativas:

§ 60 Entre outras afins, classificam-se como despesas administrativas os gastos da Unidade Gestora com pessoal próprio e os conseqüentes encargos, indenizações trabalhistas, materiais de expediente, energia, água e esgoto, comunicações, vigilância, locações, seguros, obrigações tributárias, manutenção, limpeza e conservação dos bens móveis e imóveis, consultoria, assessoria técnica, honorários, jetons a conselheiros, diárias e passagens de dirigentes e servidores a serviço da unidade gestora, cursos e treinamentos.

Observado o limite de dois pontos percentuais do valor total da remuneração, proventos e pensões dos segurados vinculados ao regime próprio de previdência social, 
relativamente ao exercício financeiro anterior, poderá ainda a Unidade Gestora, mediante deliberação da instância coletiva de decisão, adquirir os bens móveis do grupo 1.4.2.1.2.00.00 ${ }^{5}$, constante da Estrutura do Plano de Contas aprovado pela Portaria MPS no 916, de 15 de julho de 2003 e alterações posteriores, exceto veículos, seus acessórios e peças, nos termos preceituados pelo § 70 do art. 17 da Portaria no 4.992/99, acrescentado pela Portaria no 1.348, de 19/07/2005, publicada no D. O. U. de 21/07/2005.

\section{Conclusão}

A Taxa de Administração figura assim como uma exceção na destinação dos recursos previdenciários, primordialmente destinados ao custeio dos benefícios, podendo ocorrer mediante a utilização de recursos previdenciários ou de repasses além dos recursos previdenciários, sendo-lhe facultada a possibilidade de constituição de reservas com eventuais sobras do custeio administrativo.

A alteração da Portaria no 4.992/99, permitindo a constituição de reservas com eventuais sobras, bem como a ampliação do rol dos elementos passíveis de aquisição significaram para os Regimes de Previdência uma tênue, mas significativa conquista na autonomia de gerência do Regime Próprio.

A doutrina jurídica acerca do tema se encontra sensivelmente limitada a publicações do próprio Ministério da Previdência Social por intermédio da sua Secretaria de Previdência Social e dos Tribunais de Contas, sujeita a freqüentes modificações legais.

\section{Referências}

BRASIL. Ministério da Previdência e Assistência Social. A Lei de Responsabilidade Fiscal e a Previdência dos Servidores Públicos Municipais. Brasília: MPAS / SPS, 2001.

BRASIL. Ministério da Previdência e Assistência Social. Gushiken, L. Regime Próprio de Previdência dos Servidores: como implementar? Uma visão prática e teórica. Brasília: MPAS, 2002.

\footnotetext{
5 Aparelhos e Utensílios Domésticos; Coleções e Materiais Bibliográficos; Equipamento de Proteção, Segurança e Socorro; Máquinas e Equipamentos Gráficos; Equipamentos para Áudio, Vídeo e Foto; Máquinas, Utensílios e Equipamentos Diversos; Equipamentos de Processamento de Dados; Máquinas, Instalações e Utensílios de Escritório; Equipamentos Hidráulicos e Elétricos; Mobiliário em Geral; Veículos Diversos; Veículos de Tração Mecânica; Acessórios para Automóveis; e, Material de Uso Duradouro.
} 
BRASIL. Ministério da Previdência e Assistência Social. Rabelo, F. Regimes Próprios de Previdência: Modelo Organizacional, Legal e de Gestão de Investimentos. Brasília: MPAS / SPS, 2001.

DI PIETRO, Maria Sylvia Zanella. Direito administrativo. 11. ed. São Paulo: Atlas, 1999.

JUSTEN FILHO, M. Curso de direito administrativo. São Paulo: Saraiva, 2005.

MEIRELLES, H. Direito Administrativo Brasileiro. 27. ed. São Paulo: Malheiros , 2002.

. Direito Municipal Brasileiro. 12. ed. São Paulo: Malheiros Editores, 2001.

MELLO, Celso Antônio Bandeira de. Curso de direito administrativo. 17. ed. São Paulo: Malheiros, 2004.

TRIBUNAL DE CONTAS DO ESTADO DO PARANÁ. Manual Previdenciário Atualizado: Manual Técnico e Operacional - Regimes Próprios de Previdência Social e Sistemas Previdenciários. Curitiba: 2004.

TRIBUNAL DE CONTAS DO ESTADO DO PARANÁ. Questões pertinentes ao orçamento de 2005. [s. I]: [s. d]. 
Revista de DiReito Público, LondRINA, v. 1, N. 3, P. 231-242, Set./dez. 2006. 